Research Article

\title{
A prospective study of the pattern of non-antimicrobial drug use in neonatal intensive care management in a tertiary care hospital
}

\author{
Anitha P. $^{1}{ }^{*}$, Pundarikaksha H. . $^{2}$, Yashoda H. T. ${ }^{3}$
}

${ }^{1}$ Department of Pharmacology, Sri Siddhartha Medical College, Tumkur, Karnataka, India ${ }^{2}$ Department of Pharmacology, ${ }^{3}$ Department of Pediatrics, Kempegowda Institute of Medical Sciences, Bangalore, Karnataka, India

Received: 21 April 2016

Revised: 04 June 2016

Accepted: 09 June 2016

*Correspondence to:

Dr. Anitha P,

Email: anitaprabhu16

@gmail.com

Copyright: () the author(s), publisher and licensee Medip Academy. This is an openaccess article distributed under the terms of the Creative Commons Attribution NonCommercial License, which permits unrestricted noncommercial use, distribution, and reproduction in any medium, provided the original work is properly cited.

\begin{abstract}
Background: Neonatal intensive care management (NICM) may be required for high risk or critically ill neonates for survival or stabilization. NICM involves the use of different classes of drugs, and the pattern of use mainly determined by the prevailing clinical conditions and complications, and the desired therapeutic objectives. The objective of this study was to study the pattern of drug use in NICM, criteria for drug selection and dose individualization, to assess the efficacy and safety of medications and record drug interactions.

Methods: The pattern of drug use was assessed prospectively in 150 consecutive subjects admitted to NICU. The number of drugs used, therapeutic class, dose, route, frequency and duration of administration, criteria for selection were recorded. The efficacy and safety of the medications was assessed by the treatment outcome and by observing for any adverse events or drug interactions.

Results: Different therapeutic classes of drugs were used as per the prevailing clinical conditions or complications. The total number of drugs used was 23 . Different classes of drugs were used for specific indications. The treatment outcome was very good in most of the subjects and no drug related adverse events or interactions were observed.

Conclusions: Most of the problems and complications in high risk and critically ill neonates can be prevented or controlled by judicious use of several classes of drugs, properly chosen and individualised to the given situation, without producing serious adverse events and interactions. Drugs play an important role in improving the outcome.
\end{abstract}

Keywords: NICU, NICM, RDS

\section{INTRODUCTION}

A neonatal intensive care unit (NICU) is a highly specialized unit that provides high quality skilled care to premature, low birth weight or critically ill new born infants, those with birth defects, those born out of high risk pregnancies, and also for various complications like birth asphyxia, respiratory distress etc. ${ }^{1-4}$ About $10-15 \%$ of all neonates may require NICM. Overall survival rates following NICM is roughly about $70 \% .^{5}$

NICM involves the use of a wide range of medications like antimicrobial agents (AMAs), cardiovascular drugs, analgesics, hematological agents, endocrinal agents, CNS drugs, respiratory medications, gastrointestinal drugs, steroids, nutritional supplements, surfactants etc, given in suitable formulations by various routes., ${ }^{1,6-8}$ Premature and those born out of high risk pregnancies, are at greater risk for medication exposure. ${ }^{7}$

Because of the immaturity of various organ functions, the neonates may show pharmacokinetic and pharmacodynamics variations making them more susceptible for adverse drug reactions. In addition, the use of multiplicity of medications may also predispose for the potential risk of adverse drug interactions. ${ }^{9,10}$ It is often difficult to detect and monitor the adverse effects of drugs in neonates. 
In spite of many advances in neonatal clinical pharmacology, there is still a paucity of adequate information to guide rational prescribing in the NICM. Moreover the use of some drugs is "off-label" i.e. beyond the approved indications, and also their absolute safety yet to be established in high risk neonates. ${ }^{6}$ There are no standard guidelines for drug prescribing in NICM in most of the hospitals.

The pattern and extent of drug utilization in NICM may vary considerably in different countries and centres according to the prevailing perinatal/neonatal problems and complications, which therefore merits a systematic evaluation. Since there are a few systematic studies and reports from Indian hospitals regarding the pattern and extent of drug utilization, the present study was taken up with the purpose of generating some valid data and useful information for improving the quality of nonantimicrobial drug prescribing.

The objective of this study was to study the pattern of non-antimicrobial drug use in NICU. And to assess the criteria for drug selection and individualization of dose and to assess the efficacy and safety of medications and record drug interactions, if any.

\section{METHODS}

Neonates admitted to NICU and receiving one or more medications, were included in the present study. Approval and clearance from the Institutional Ethics Committee was obtained before starting the study. Written informed consent was obtained from parents/legal representatives of all the study subjects after fully explaining the study procedure to their satisfaction, in both English and vernacular language. This study was carried out over a period of 18 months. Purposive sampling was done.

\section{Inclusion criteria}

- All neonates admitted to NICU and receiving one or more medications

- Willingness of parents/legal representatives to give written informed consent.

\section{Exclusion criteria}

- Neonates not receiving any medications other than AMAs, fluids/electrolyte solution, parenteral nutrition, nutritional supplements, blood and blood products, oxygen, phototherapy, vitamin $\mathrm{K}$ prophylaxis, vaccinations or ophthalmic prophylaxis.

- Neonates who were discharged or died within 24 hours of NICU admission.

\section{Study procedure}

The gestational age, birth weight, gender, obstetric history, type of delivery, the reason for admission, the clinical diagnosis, laboratory data, the duration of stay and discharge status were recorded. The details of medication i.e., number of drugs used, the therapeutic class/category of drugs, the dose, route, frequency and duration of administration, the criteria for drug selection and dose individualization were documented. The efficacy of the medications was assessed by the treatment outcome and safety/tolerability by monitoring and recording any adverse events. Any drug interactions among the study medications were also recorded. AMAs, fluids and electrolyte solutions, parenteral nutrition, nutritional supplements, prophylactic vitamin K, oxygen administration, immunizations, phototherapy and prophylactic ophthalmic treatment, were not considered for data analysis. All the relevant data were entered and documented in case record forms (CRF).

\section{Statistical analysis}

The data collected was analysed by using descriptive statistics, namely mean and standard deviation for quantitative variables. The results were also depicted in the form of tables and graphs. Microsoft Word and Excel were used for the analysis of data and to generate graphs and tables.

\section{RESULTS}

Table 1 shows the demographic data of the study population. The mean age of neonates in days on admission to NICU was $3.44 \pm 2.47$. Majority of the subjects $(86.6 \%)$ were in the age group of 1-7 days, indicating that most of the critical situations and complications commonly occur in the early neonatal period. The mean gestational age of the admitted neonates was $35.21 \pm 2.00$ weeks. $45 \%$ of the subjects were of full term, $36.66 \%$ late preterm and only $16.6 \%$ being very preterm. This was consistent with the observations in other studies. $^{7} 62 \%$ of the subjects were male, as also observed in other studies. ${ }^{2}$ Nearly $48.6 \%$ of the subjects admitted to NICU were out-born, transferred from other centres.

The mean birth weight was $2.20 \pm 0.77 \mathrm{~kg}$, and $57.93 \%$ of the subjects in the low birth weight range (1.0-2.4 kg). Similar observations were made in other studies. ${ }^{4,6}$ There seems to be a good correlation between low birth weight and NICU admission. $88 \%$ of the admitted neonates were of singleton birth, consistent with other observations. ${ }^{8}$

Apgar score was assessed at $1 \mathrm{~min}$ and 5 min after birth $(n=137)$, and data was not available for 13 out-born neonates. The Apgar score was normal $(\geq 7)$ in $74.40 \%$ of subjects at 1 minute, and $90.60 \%$ of subjects at 5 minute. The mean score improved from $6.33 \pm 2.53$ at 1 minute to $7.45 \pm 2.67$ at 5 minutes, indicating an overall improvement in the general condition.

The mode of delivery in $56.60 \%$ of the subjects $(n=85)$ were from normal delivery, and $40.60 \%(n=61)$ from 
LSCS. Some studies have reported a higher rate of NICU admission from LSCS, probably because of the pre- existing abnormalities requiring LSCS, and maternal exposure to various drugs as part of the procedure. ${ }^{11}$

Table 1: Demographic data.

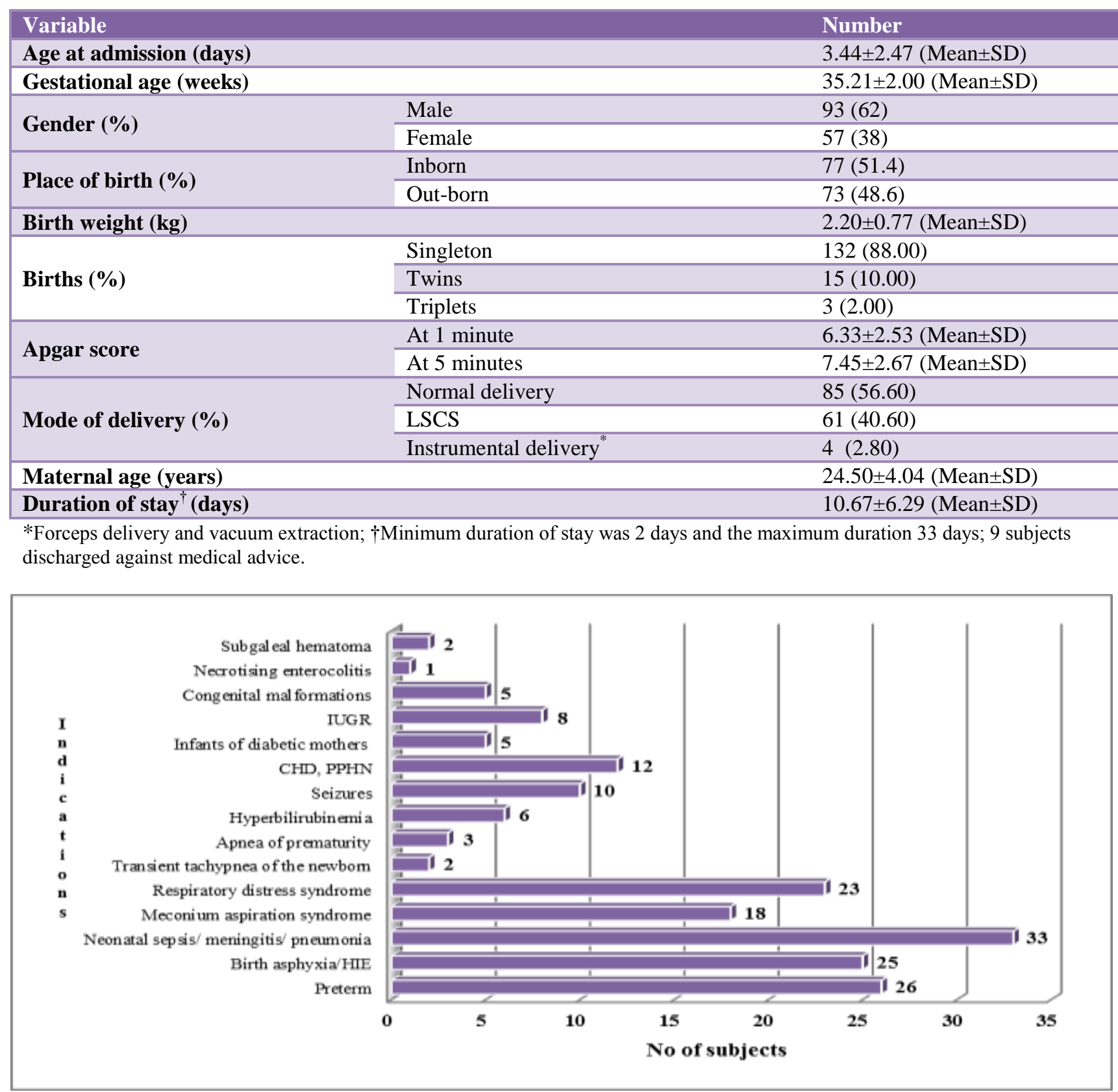

*93 (62\%) neonates had more than one indication/complication; ${ }^{\dagger}$ Physiological jaundice excluded.

Figure 1: Indications for NICU admission diagnosis/provisional diagnosis*.

The mean age of the mothers was $24.50 \pm 4.04$ years, and majority of the mothers $(84 \%)$ were in the age group between 20-29 years. The number of NICU admissions increased with maternal age, probably because of increased preterm birth and other complications. ${ }^{12,13}$ The mean duration of stay in NICU was $10.67 \pm 6.29$ days, and in $59 \%$ of the subjects $(n=89)$ the duration of stay ranged from 5 to 12 days, 44 of them being preterm. Some studies have observed a good correlation between the gestational ages, birth weight and head circumference, and the duration of stay. ${ }^{14}$ Though there was no clear correlation between birth weight and head circumference 
in the present study, premature infants required a longer duration of stay.

The indications and reasons for NICU admission are presented in Figure 1. The most common reason for admission was neonatal sepsis $(n=33)$, and the other common reasons were preterm $(n=26)$, birth asphyxia $(n=25)$ and respiratory distress syndrome (RDS) $(n=23)$. $62 \%$ of the neonates had more than one indication. $35.3 \%$ of the admissions were related to prematurity. Almost similar pattern of neonatal admissions were observed in other studies. ${ }^{1-4}$ However, in some studies, more number of admissions was due to neonatal hyper-bilirubinemia which included physiological jaundice, unlike the present study.

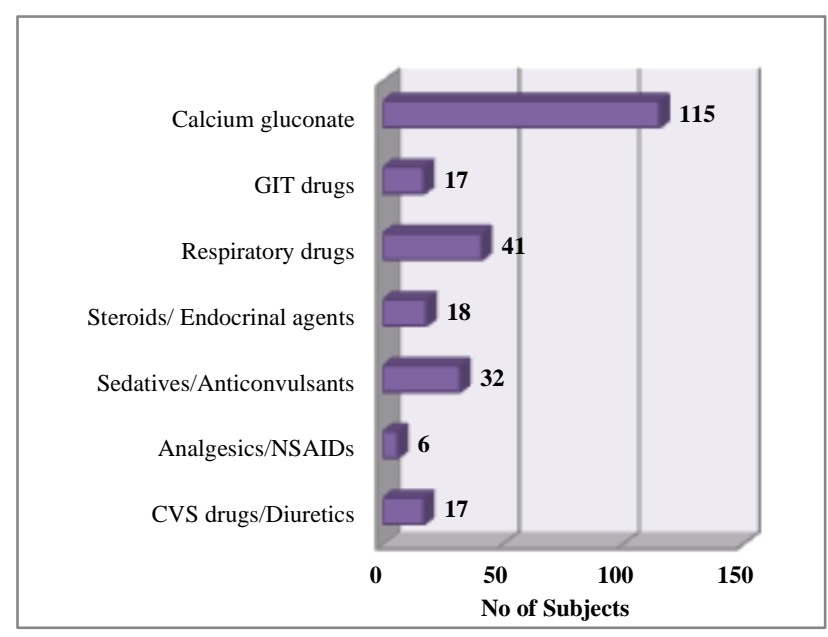

Figure 2: Exposure rates for different class of drugs.

The medication data are presented in Table 2 and Figure 2. The total number of medications used was 23. The different classes of drugs included cardiovascular drugs (9.30\%), analgesics/NSAIDs $(6.97 \%)$, sedatives and anticonvulsants $(9.30 \%)$, steroids/endocrinal agents $(6.97 \%)$, respiratory drugs $(13.95 \%)$, GIT drugs $(4.65 \%)$ and calcium gluconate $(2.32 \%)$. Other studies also have reported a similar number and range of drugs. ${ }^{6}$

Cardiovascular drugs used in NICM were inotropic agents, pulmonary vasodilators and diuretics. The inotropic agents included dopamine $(n=9)$ and dobutamine $(n=1)$. Sildenafil was used as a pulmonary vasodilator in PPHN $(n=6)$. Furosemide, was used to reduce volume overload. Other studies have also reported almost similar pattern of cardiovascular drug use. ${ }^{1,6-8}$ However, there are few reports in the literature regarding the use of sildenafil for PPHN. Since the safety of dopamine, dobutamine and sildenafil has not been established in neonates, their use can be considered as "off label". 6,8,15,16

Analgesic/NSAIDs used were Fentanyl, was used in 1 subject maintained on ventilator for analgesia. Paracetamol was used as drops, and as suppository, to control fever due to sepsis in 3 subjects. Indomethacin, was used to promote closure of PDA in 2 subjects. Similar pattern was observed in other studies. ${ }^{1,6-8}$ Fentanyl not approved for use in neonates, and hence it is an "off label" use for fentanyl. ${ }^{6}$

Sedatives and anticonvulsants used were midazolam, phenobarbitone, phenytoin and lorazepam. Midazolam was used for sedation in the neonates maintained on ventilators $(n=21)$. Phenobarbitone was used to control convulsions due to neonatal seizures, sepsis and meningitis $(n=21)$, phenytoin was used as adjuvant to phenobarbitone in 5 subjects and lorazepam (IV) in 1 subject with refractory seizures not responding to the other two drugs. Midazolam is frequently used for sedation in neonates maintained on ventilators as observed and reported in other studies. ${ }^{1,6-8}$ However, caution is required because of the risk of hypotension and IVH, more likely with bolus IV doses, hence its use in neonates may be considered "off label".,17 Phenobarbitone has been more widely used as the first line anticonvulsant in neonatal seizures and phenytoin less often, and lorazepam was reserved for refractory seizures for which it is licensed as an "off label" drug. 1,6-8 The ability of phenobarbitone to induce the microsomal glucuronyl transferase can be a particular advantage in neonates with coexisting hyperbilirubinemia.

Dexamethasone was the most commonly used glucocorticoid $(n=16)$ and budesonide used only in one subject. The glucocorticoids were used to reduce inflammation and to improve lung function in subjects with $\operatorname{RDS}(\mathrm{n}=13)$ and Meconium aspiration syndrome (MAS) $(n=4)$. The dose, frequency and duration of administration were in accordance with the standard guidelines, though an "off label" use for both the steroids. Other studies have reported the use of dexamethasone and hydrocortisone for similar indications. ${ }^{1,6,8}$ Nebulised budesonide can be of some advantage as it can ensure a selective and localized steroid effect on the lungs minimizing the adverse effects of systemic steroid administration. The other endocrinal agent used in the present study was insulin (regular), administered as IV infusion to control hyperglycemia due to sepsis in one subject. However, very few cases $(<1 \%)$ are encountered in NICM, as also observed in our study where only one subject was involved.

The most commonly used respiratory medications were bronchodilators $(\mathrm{n}=38)$ which included aminophylline $(n=20)$, adrenaline $(n=11)$ and salbutamol $(n=7)$. The other drugs used were beractant $(n=7)$, caffeine citrate $(n=3)$ and acetylcysteine $(n=1)$. The bronchodilators were used in subjects with RDS, MAS, pneumonia and apnea of prematurity (AOP) to reduce dyspnea, respiratory distress and to improve lung compliance. Caffeine citrate $(n=3)$ was used in AOP as respiratory stimulant. Beractant, a pulmonary surfactant of bovine origin, was used in 7 subjects with RDS by intra-tracheal instillation as single dose $(n=6)$ and 2 doses $(n=1)$. Beractant was preferred for use in the present study, since animal 
derived surfactants are claimed to be better in reducing surface tension than the synthetic derivatives. ${ }^{18}$ Acetyl cysteine, was used as a mucolytic in one subject with bronchopneumonia. The overall pattern of respiratory medication usage in the present study was consistent with that of other studies, and conformed very well with the standard procedure. ${ }^{1,6-8,19}$ However, AOP is an "off label" use for aminophylline as it is not approved for this condition.

Table 2: Drugs used in neonates.

\begin{tabular}{|c|c|c|c|c|}
\hline Drug class & Generic name & Dosage & $\begin{array}{l}\text { Duration of } \\
\text { administration in } \\
\text { days }(\text { Mean } \pm \text { SD) }\end{array}$ & $\begin{array}{l}\text { No. of } \\
\text { subjects } n\end{array}$ \\
\hline \multirow{4}{*}{ CVS/diuretics } & Dopamine & IV infusion $15 \mu \mathrm{g} / \mathrm{kg} /$ minute & $5.49 \pm 4.17$ & 9 \\
\hline & Dobutamine & IV infusion $15 \mu \mathrm{g} / \mathrm{kg} /$ minute & 3.00 days & 1 \\
\hline & Sildenafil & $2 \mathrm{mg} / \mathrm{kg}$ BID oral & $6.33 \pm 4.59$ & 6 \\
\hline & Furosemide & $1 \mathrm{mg} / \mathrm{kg}$ IV BID & $6.33 \pm 4.55$ & 5 \\
\hline \multirow{3}{*}{ Analgesics/NSAIDs } & Fentanyl & IV infusion $1 \mu \mathrm{g} / \mathrm{kg} / \mathrm{hour}$ & 3 days & 1 \\
\hline & Paracetamol & $10 \mathrm{mg} / \mathrm{kg}$ oral/rectal & $2.67 \pm 2.08$ & 3 \\
\hline & Indomethacin & $0.2 \mathrm{mg} / \mathrm{kg} \mathrm{IV}$ & 3 doses & 2 \\
\hline \multirow{4}{*}{ Sedatives/anticonvulsants } & Midazolam & IV infusion $1 \mu \mathrm{g} / \mathrm{kg} /$ minute & $5.48 \pm 4.28$ & 21 \\
\hline & Phenobarbitone & $5 \mathrm{mg} / \mathrm{kg} / \mathrm{day}$ IV BID & $7.22 \pm 4.64$ & 21 \\
\hline & Phenytoin & $15 \mathrm{mg} / \mathrm{kg} /$ day IV & $5.31 \pm 3.79$ & 5 \\
\hline & Lorazepam & $0.05 \mathrm{mg} / \mathrm{kg}$ IV OD & 3 days & 1 \\
\hline \multirow{3}{*}{ Steroids/endocrinal agents } & Dexamethasone & $0.25 \mathrm{mg} / \mathrm{kg}$ IV BID/TID & $5.22 \pm 3.91$ & 16 \\
\hline & Budesonide & $0.5 \mathrm{mg}$ BID by nebulisation & 6 days & 1 \\
\hline & Insulin & IV infusion $0.05 \mathrm{U} / \mathrm{kg} / \mathrm{hour}$ & 1 day & 1 \\
\hline \multirow{6}{*}{ Respiratory drugs } & Acetylcysteine & $1 \mathrm{ml}$ BID by nebulisation & 6 days & 1 \\
\hline & Adrenaline & $0.02 \mathrm{mg} / \mathrm{kg}$ QID by nebulisation & $4.73 \pm 4.31$ & 11 \\
\hline & Aminophylline & $\begin{array}{l}\text { Loading dose } 6 \mathrm{mg} / \mathrm{kg} \text { IV } \\
\text { Maintenance dose } 2 \mathrm{mg} / \mathrm{kg} \text { IV TID }\end{array}$ & $6.41 \pm 4.62$ & 20 \\
\hline & Caffeine citrate & $5 \mathrm{mg} / \mathrm{kg}$ IV OD & 6 days & 3 \\
\hline & Salbutamol & $0.1 \mathrm{ml} / \mathrm{kg}$ QID by nebulisation & $6.32 \pm 4.67$ & 7 \\
\hline & Beractant & $4 \mathrm{ml} / \mathrm{kg}$ by intra-tracheal instillation & $\begin{array}{l}\text { Single dose } \\
\text { Two doses }\end{array}$ & 7 \\
\hline \multirow{2}{*}{ GIT drugs } & Domperidone & $0.3 \mathrm{mg} / \mathrm{kg}$ Oral TID & $5.70 \pm 4.48$ & 7 \\
\hline & Ranitidine & $0.5 \mathrm{mg} / \mathrm{kg}$ IV TID & $5.61 \pm 4.38$ & 10 \\
\hline Calcium gluconate & & $1 \mathrm{ml} / \mathrm{kg}$ IV TID & $6.92 \pm 4.39$ & 1 \\
\hline
\end{tabular}

The gastrointestinal drugs used in the present study included domperidone and ranitidine. Ranitidine, was used for prevention of stress ulcerations in subjects with sepsis and necrotizing enterocolitis $(n=10)$, and domperidone as the prokinetic agent in subjects with feeding intolerance and regurgitation $(n=7)$. Ranitidine was the only $\mathrm{H} 2$ blocker used in other studies, and metoclopramide was used as prokinetic, though ranitidine is not approved for use in neonates. ${ }^{6,8}$ There are few reports regarding the use of domperidone and it is not approved for use in neonates because of the concerns about extrapyramidal adverse effects and QT prolongation. ${ }^{20}$ However, in the present study it was preferred to metaclopramide for the possible reason that it is less likely than the latter drug to cross the blood brain barrier and to cause extrapyramidal toxicity, even considering the fact that the blood brain barrier is not fully established in neonates. The overall risk of extrapyramidal effects is potentially high with metoclopramide which prompted the FDA to issue a black box warning in $2009 .{ }^{20}$ Hence, the use of domperidone in the present study in preference to metoclopramide seems to be justified. Calcium gluconate was used in $76.6 \%$ subjects $(n=115)$ to correct hypocalcemia $(n=15)$, to control hypocalcemic seizures $(\mathrm{n}=2)$ and prophylactically $(n=98)$ in subjects showing jitteriness and irritability. Even in several other studies calcium gluconate was found to be the most commonly used medication. ${ }^{1,7,8}$

The common use of calcium gluconate appears to be justified as early neonatal hypocalcemia is a common problem in preterm infants. This can be correlated with 
delayed surge of parathormone secretion and higher levels of calcitonin in preterm as compared to term neonates. ${ }^{21}$

The exposure rate for different classes of drugs is shown in Figure 2. The highest rate of exposure was for calcium gluconate $(76.66 \%)$. Most of the other studies have also shown a higher rate of exposure to calcium gluconate. ${ }^{1,6,7}$

Table 3: Treatment outcome $(n=150)$.

\begin{tabular}{|c|c|}
\hline Outcome & No. of subjects n (\%) \\
\hline Improved * & $139(92.66)$ \\
\hline Not available for assessment ${ }^{\dagger}$ & $9(6.00)$ \\
\hline Death $^{\#}$ & $2(1.33)$ \\
\hline $\begin{array}{l}\text { *Condition stabilized and shifted } \\
\text { with CHD and other malformat } \\
\text { intervention; †As the subjects } \\
\text { medical advice; \#One preterm } \\
\text { admission due to pulmonary haem } \\
\text { to birth asphyxia and respiratory } \mathrm{P}\end{array}$ & $\begin{array}{l}\text { out of NICU; } 3 \text { subjects } \\
\text { ons referred for surgical } \\
\text { were discharged against } \\
\text { ibject died } 4 \text { days after } \\
\text { rrrhage, and the other due } \\
\text { llure after } 2 \text { days. }\end{array}$ \\
\hline
\end{tabular}

The treatment outcome is summarized in Table 3. $92.66 \%$ of the subjects $(n=139)$ showed good clinical improvement with stabilized condition, and were shifted out of NICU. 3 subjects with CHD and other malformations were referred for surgical intervention. However, death occurred in 2 subjects, one preterm neonate died 4 days after admission due to pulmonary haemorrhage, and the other due to birth asphyxia and respiratory failure after 2 days. 9 subjects $(6 \%)$ were not available for further assessment as they were discharged against medical advice for various reasons. Similar outcome were observed in other studies. ${ }^{7,8}$ Hence, it may be reasonable to assume that good NICM significantly contributes for survival of the critically ill neonates. Though the non-pharmacological aspects of management like incubation, ventilation, oxygenation, phototherapy, nutrition play a greater role in promoting survival, the use of drugs with specified objectives may also contribute significantly. All the medications used during NICM appeared to have good tolerability with no drug related serious adverse event or drug interactions, though it may be difficult to assess such events in critically ill neonates. Other studies also have not observed any drug related serious adverse events. ${ }^{1,6}$

The laboratory investigations on admission and repeated as needed, helped to confirm the diagnosis, to detect other abnormalities and also to monitor the treatment response and progress.

\section{DISCUSSION}

In the present study majority of the admissions were due to prematurity, birth asphyxia, sepsis and respiratory distress, and the duration of stay was related to the preexisting or ongoing disease states or complications, and treatment response. ${ }^{1-4}$ The total number of drugs used was 23 , of which 13 drugs $(56.5 \%)$ are approved for neonatal use, and for the other 10 drugs it was an "off label" use. ${ }^{6}$ The preterm and ventilated neonates generally required higher number of drugs. Majority of the drugs were administered by IV route, and less commonly oral, rectal, topical and inhalational route, the latter route preferred for respiratory medications.

The different therapeutic classes of drugs(excluding AMAs) included cardiovascular drugs, analgesics, sedatives and anticonvulsants, glucocorticoids, insulin, bronchodilators, surfactant, mucolytics, H2 blockers, prokinetics and calcium gluconate. ${ }^{6}$

Analgesics and NSAIDs were required only in a few subjects (4\%), indicating that these drugs are needed less often. Fentanyl appears to be the most suitable opioid analgesic for IV infusion, because of the rapid onset of action and short duration of action. Oral/rectal paracetamol is the most appropriate antipyretic to control fever due to sepsis or other reasons, and indomethacin, is the preferred drug for the closure of PDA, as it is established and approved for this condition. ${ }^{1,6-8}$

Midazolam appears to be effective and safe for parenteral sedation in subjects maintained on ventilators. Convulsions in neonates can be effectively controlled by phenobarbitone, with phenytoin as adjuvant in selected cases. Lorazepam can be reserved for refractory seizures. ${ }^{1,6-8}$

Glucocorticoids can be used by IV injection or nebulisation to reduce the inflammation and edema, and to improve lung function and alveolar ventilation in neonates with RDS and MAS. Budesonide nebulisation can be considered as an alternative to IV glucocorticoids to avoid the systemic adverse effects. IV infusion of regular insulin can be considered for neonatal hyperglycemia. ${ }^{1,6,8}$

The use of bronchodilators by nebulisation appears to be very appropriate and the other routes may be considered, if pulmonary route is ineffective. Caffeine citrate was found to be very effective and safe, and hence considered the most suitable option for AOP because of its good margin of safety. Beractant, a surfactant was very effective to improve lung function in RDS., ${ }^{1,6-8,19}$

Domperidone, was very effective in preventing regurgitation due to feeding intolerance. Ranitidine was used to prevent stress ulceration due to sepsis and necrotizing enterocolitis, though not approved for use in neonates, has a good safety profile. ${ }^{6,8}$ Calcium gluconate was used in most of the subjects $(n=115)$. Hence routine calcium supplementation in the neonates is a usual and widely accepted practice in NICUs, which can be considered as justified. ${ }^{1,7,8}$

Treatment response was very good in $92.66 \%$ of the subjects $(n=139)$, such that their condition stabilized and hence not requiring NICU, indicating that apart from various life support systems and other physical facilities, 
the use of various drugs as required for the given situation, might have played an important role in survival and homeostatic stabilization. There were no serious adverse events related to drug therapy, though it may be very difficult to assess such events during critical care management in neonates.

The various routine and special investigations done at baseline may be useful not only to confirm the diagnosis but also to detect the associated abnormalities, and to determine the most appropriate therapy, and in addition, to assess the treatment response and progress, by repeating the investigations as found necessary.

Thus it can be concluded by the observations of the present study, that the different classes of drugs chosen by well-defined therapeutic objectives play an important role in the stabilization and survival of the critically ill neonates. All the drugs used in the present study appeared to be effective and safe, and no adverse drug interactions were observed. Further more elaborate studies may help to formulate appropriate treatment guidelines, optimized and individualized to the given situation.

\section{CONCLUSION}

- $\quad$ NICM involves the use of different classes of drugs with well-defined therapeutic objectives, to address the prevailing problem or complication.

- The total number of drugs used was 23. Different classes of drugs such as inotropic agents, vasopressors, pulmonary vasodilators, diuretics, bronchodilators, surfactants, mucolytic, glucocorticoids, analgesics, sedatives, anticonvulsants, insulin, $\mathrm{H} 2$ blockers, pro-kinetics and calcium gluconate, may be required to address the prevailing or associated complication.

- The most preferred route for drug administration in NICM is intravenous, and other routes such as oral, rectal pulmonary and topical, may be employed depending upon the drug used and the desired site of action.

- The judicious use of various drugs significantly contributes to improve the treatment outcome, without adverse events and interactions.

Funding: No funding sources

Conflict of interest: None declared

Ethical approval: The study was approved by the Institutional Ethics Committee

\section{REFERENCES}

1. Uppal R, Chhabra A, Narang A. Pattern of drug use in neonatal intensive care unit. Indian Pediatrics. 1998;35:647-9.

2. Kumar M, Thakur S, Singh B. Study of the morbidity and the mortality patterns in the neonatal intensive care unit at a tertiary care teaching hospital in Rohtas
District, Bihar, India. Journal of Clinical and Diagnostic Research. 2012;6(2):282-5.

3. Narayan R. A study of the pattern of admissions and outcome in a neonatal intensive care unit at high altitude. Sri Lanka Journal of Child Health. 2012;41(2):79-81.

4. Rahim F, Jan A, Mohummad J, Iqbal H. Pattern and outcome of admissions to neonatal unit of Khyber teaching hospital, Peshawar. Pak j med sci. 2007;23(2):249-53.

5. Neonatal intensive care unit. Available at http://en.wikipedia.org/wiki/Neonatal_intensive_care _unit. Accessed on 13 May 2013.

6. Kumar P, Walker JK, Hurt KM, Bennett KM, Grosshans N, Fotis MA. Medication use in the neonatal intensive care unit: current patterns and offlabel use of parenteral medications. J Pediatr. 2008;152:412-5.

7. Warrier I, Du W, Natarajan G, Salari V, Aranda J. Patterns of drug utilisation in a neonatal intensive care unit. J Clin Pharmacol. 2006;46:449-55.

8. Clark RH, Bloom BT, Spitzer AR, Gerstmann DR. Reported medication use in the neonatal intensive care unit: data from a large national data set. Pediatrics. 2006;117:1979-87.

9. Koren G. Special aspects of perinatal and pediatric pharmacology. In: Katzung BG, Masters SB, Trevor AG, editors. Basic and Clinical Pharmacology. $12^{\text {th }}$ ed, New Delhi: Mc Graw Hill; 2012:1039-1050.

10. Walson PD. Pediatric clinical pharmacology and therapeutics. In: Speight TM, Holford NHG, editors. Avery's drug treatment $4^{\text {th }}$ ed, Adis press; 1997:127171.

11. Kamath BD, Todd JK, Glazner JE, Lezotte, Lynch AM. Neonatal Outcomes after Elective Caesarean Delivery. Obstet Gynecol. 2009;113:1231-8.

12. Jongh BE, Locke R, Paul DA, Hoffman M. The differential effects of maternal age, race/ethnicity and insurance on neonatal intensive care unit admission rates. BMC Pregnancy and Childbirth. 2012;12:97.

13. Lisonkova S, Janssen PA, Sheps SB, Lee SK, Dahlgren L. The effect of maternal age on adverse birth outcomes: Does parity matter? J Obstet Gynecol Can. 2010;32(6):541-8.

14. Pepler PT, Uys DW, Nel DG. Predicting mortality and length of stay for neonatal admissions to private hospital neonatal intensive care units: a Southern African retrospective study. African Health Sciences. 2012;12(2):166-73.

15. Noori S, Seri I. Neonatal blood pressure support: the use of inotropes, lusitropes, and other vasopressor agents. Clin Perinatol. 2012;39:221-38.

16. Baquero H, Soliz A, Neira F, Venegas ME, Sola A. Oral Sildenafil in infants with persistent pulmonary hypertension of the newborn: a pilot randomized blinded study. Paediatrics. 2006;117(4):1077-83.

17. Hall RW, Shbarou RM. Drug of choice for sedation and analgesia in the neonatal ICU. Clin Perinatol. 2009;36:215-26. 
18. McDonald CL, Ainsworth SB. An update on the use of surfactant in neonates. Current Paediatrics. 2004; $14: 284-9$

19. Neubert A, Lukas K, Leis T, Dormann H, Brune K, Rascher W. Drug utilization on a preterm and neonatal intensive care unit in Germany: a prospective, cohort based analysis. Eur J Clin Pharmacol. 2010;66:87-95.
20. Malcolm WF, Cotton M. Metoclopramide, H2 blockers, and proton pump inhibitors: pharmacotherapy for gastroesophageal reflux in neonates. Clin Perinatol. 2012;39:99-109.

21. Rao ND, Bavdekar SB, Raghunandana KG, Joshi SY, Hathi GS. Calcium supplement for preterm and low birth weight neonate. Indian Pediatrics. 1994;31:65760 .

Cite this article as: Anitha $\mathrm{P}$, Pundarikaksha HP, Yashoda HT. A prospective study of the pattern of non-antimicrobial drug use in neonatal intensive care management in a tertiary care hospital. Int J Basic Clin Pharmacol 2016;5:1372-9. 